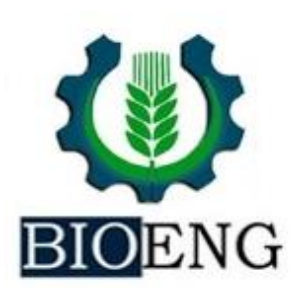

\section{APLICAÇÃO DA ESTRATÉGIA OPEN INNOVATION NA AGRICULTURA MUNDIAL: CONTRIBUIÇÕES A PARTIR DE REVISÃO SISTEMATIZADA DA LITERATURA}

\author{
F. L. Agudo *1, G. A. Santini Pigatto ${ }^{2}$, J. A. Gobbo Júnior ${ }^{1}$, R.
} D. Baptista ${ }^{2}$, T. R. Queiroz ${ }^{2}$

\author{
${ }^{1}$ Faculdade de Engenharia de Bauru - FEB, Unesp Campus de Bauru - SP, Brasil \\ ${ }^{2}$ Faculdade de Ciências e Engenharia - FCE, Unesp Campus de Tupã - SP, Brasil
}

Article history: Received 09 June 2020; Received in revised form 15 July 2020; Accepted 11 September 2020; Available online 30 September 2020.

\title{
RESUMO
}

A crescente população mundial exige que as organizações se preparem para servir o mercado com alimentos saudáveis, em larga escala e com processos de produção mais limpos. A inovação no ambiente rural também otimiza a eficiência dos sistemas agroalimentares, do solo e dos recursos hídricos, e gera competitividade para os agentes do campo. Diante desse contexto, o objetivo do artigo é apresentar os resultados de uma revisão sistematizada da abordagem da inovação aberta na agricultura. Como resultado, ações de design, inovação, cadeia de valor, gestão do conhecimento, redes e partes interessadas podem facilitar a inovação aberta na agricultura. Os dados indicam que a pesquisa é conduzida por países desenvolvidos e, em geral, a inovação aberta é abordada sem especificar o tipo de inovação gerada. $O$ estudo da inovação aberta na agricultura está em estágio embrionário e é necessário aprofundar a pesquisa teórica e empírica para fortalecer as organizações ativas no setor.

Palavras-chave: Inovação aberta. Agricultura. Concorrência. Revisão de literatura.

\section{OPEN INNOVATION STRATEGY APPLICATION IN WORLD AGRICULTURE: CONTRIBUTIONS FROM A LITERATURE SYSTEMATIC REVIEW}

\begin{abstract}
The growing world population requires organizations to prepare themselves to serve the market with healthy foods, on a large scale, and with cleaner production processes. Innovation in the rural environment optimizes the efficiency of the agricultural chain, the soil and water resources, and generate competitive for the agents of the field. Facing this context, the objective of the article is to present the results of a systematic review of the open innovation approach in agriculture. As a result, actions of design, innovation, value chain, knowledge management, networks, and stakeholders can facilitate open innovation in agriculture. The data indicate that the research is conducted by developed countries, and in general, open innovation is addressed without specifying the type of innovation generated. The study of open innovation in agriculture is in its embryonic stage, and it is necessary to deepen theoretical and empirical research to strengthen organizations active in the sector.
\end{abstract}

Keywords: Open Innovation. Agriculture. Competition. Literature Review.

*fabiana.liar@ifsp.edu.br 


\section{INTRODUÇÃO}

O estudo da atividade agrícola ganhou força neste século XXI, principalmente para garantir maior eficiência na produção mundial, abrindo-se a possibilidade da inovação na agricultura como fator chave para a superação dos desafios de segurança alimentar e mudanças climáticas (DRAGONE et al., 2020; MICHLER, 2020; OSORIO-GARCÍA et al., 2020).

Pesquisas recentes da Organização das Nações Unidas (ONU) indicam que a população mundial deve atingir a marca de 9,8 bilhões de pessoas no mundo em 2050, estabilizando-se no ano de 2100 com um número estimado de 11,2 bilhões, portanto, o volume de alimentos a serem produzidos no mundo para atender à população aumentará em aproximadamente $70 \%$ (FAO, 2017; 2020).

Apostar em novas tecnologias auxilia a aumentar a produção (por meio de produtividade), muda a ordem dos grandes players rurais nos mercados e faz dos diversos agentes, direta $\mathrm{e}$ indiretamente relacionados aos sistemas agroalimentares, uma referência para a inovação no campo. Dessa forma, os preceitos de inovação aberta são bemvindos ao setor, permitindo a integração de parceiros na geração de novos produtos e processos agrícolas.

Chesbrough introduziu inicialmente o conceito de inovação aberta em 2003, sendo considerado o autor uma referência na temática. Para esse autor, inovação aberta é a coleção de recursos para inovar usando fontes internas e externas de conhecimento, uma vez que uma organização não detém facilmente à disposição todos os recursos humanos, materiais, financeiros e naturais necessários para inovar (CHESBROUGH, 2006; CHESBROUGH \& GARMAN, 2009).
Borges et al. (2018) pressupõem que para inovar as organizações precisam estar ligadas a outras partes interessadas, para ter uma visão mais completa do processo criador, de como a inovação pode ser feita de maneira mais eficiente e eficaz.

A inovação é uma estratégia que desperta os olhos de empresários e pesquisadores acadêmicos. Seus efeitos positivos são reconhecidos nos mercados e sua capacidade de gerar diferenciação dos concorrentes e criar valor para o cliente é objeto de estudos em todo o mundo (TEECE et al., 1997; KWON, 2020; KHAN \& BOHNSACK, 2020; LECKEL et al., 2020).

Todavia, dada a especificidade da atividade agrícola, o produtor rural tem várias dificuldades para inovar, como: obtenção de crédito, baixa escolaridade, acesso a informações deficientes, perfil de aversão ao risco, a existência de disparidades nas propriedades no tocante ao espaço e à cultura, restrições à efetivação da gestão do conhecimento, adaptação de novas tecnologias e treinamento do trabalho (LONG et al., 2016; PIVOTO et al., 2018).

Apesar das dificuldades que a inovação apresenta no setor agrícola, novas janelas de oportunidades, como por exemplo, transgênicos, nanotecnologia e produção de alimentos nutracêuticos ${ }^{1}$ precisam ser investigadas (BARTOLUCCI et al., 2020; LIU et al., 2020; NILE et al., 2020).

A inovação aberta modifica e agrega atributos ao processo tradicional de inovação, podendo ser utilizada em qualquer linha de negócios, inclusive,

\footnotetext{
${ }^{1}$ Segundo Moraes \& Colla (2006, p. 109) alimento nutracêutico "são alimentos ou parte dos alimentos que apresentam benefícios à saúde, [...] desde os nutrientes isolados, suplementos dietéticos até produtos projetados, produtos herbais $\mathrm{e}$ alimentos processados".
} 
na agricultura, como mostram os estudos de Medeiros et al. (2017) e Chege \& Wang (2019).

Embora a aplicação da inovação aberta seja atual e traga vários benefícios para as empresas, a colaboração, recomendada por essa estratégia, precisa ser fortalecida, de acordo com Chesbrough et al. (2018). Para isso, é necessário entender o processo de criação e captura do valor de cada agente que se aproxima para inovar.

Com base em sua relevância para a agricultura mundial, Berthet et al. (2018) sinalizam a necessidade de promover novos estudos envolvendo a inovação aberta. Para Ochara \& Moro (2018), Villa-Henriksen et al. (2020) e Zhao et al. (2020) a inovação aberta ajuda as empresas a enfrentarem os desafios da digitalização e as futuras mudanças da quarta revolução industrial. Dessa forma, pesquisas adicionais são necessárias para diluir as barreiras da inovação aberta,

\section{MATERIAIS E MÉTODOS}

O artigo consiste em uma revisão bibliográfica sistematizada que, segundo Biolchini (2007), é um instrumento para identificar os trabalhos literários publicados sobre um determinado tópico de pesquisa. Para encontrar os materiais disponíveis na literatura foram utilizadas as bases de dados online Web of Science e Scopus. A base Scopus foi escolhida por ser a maior base de dados de resumos e citações revisada por pares (SCHOTTEN et al., 2017), e a Web of Science selecionada por ser um banco de dados que apresenta métricas importantes à qualidade dos periódicos (ZHU; LI, 2020).

Baseado na literatura, os strings de busca foram: (("open innovation" OR “Open Innovation") AND $\left.\left(a g r^{*}\right)\right)$. Por usar o termo agr* de maneira principalmente no setor agrícola (DAHABIEH et al., 2018).

Nesse contexto, o objetivo do artigo é apresentar os resultados de uma revisão sistematizada da abordagem da inovação aberta na agricultura. Os artigos encontrados na literatura disponível foram classificados, codificados e categorizados para entender o panorama do estudo acadêmico no contexto da inovação aberta.

Como contribuição científica são apresentadas indicações de pesquisas futuras, como também é apresentada a análise em rede de palavras-chave, tópicos recorrentes de pesquisa $\mathrm{e}$ tópicos menos frequentes, que necessitam ser investigados.

Este trabalho está segmentado na seção 1, com a introdução e objetivo; na seção 2, com o método de pesquisa adotado; na seção 3, com as discussões relevantes e, na seção 4, com as considerações finais, limitações e pesquisas futuras.

ampla, engloba-se os termos "agriculture", "agribusiness" e "agriculture e agribusiness", logo, considera-se os termos de busca suficientes para esta revisão. Os termos foram pesquisados no título do artigo, resumo e palavras-chave.

No primeiro momento da pesquisa, visando-se identificar os subtemas do estudo, foi utilizado $o$ estudo de palavras-chave e analisado o mapa de rede de ocorrência de palavras por meio do software VOSviewer. Isso permite analisar redes bibliométricas e criar mapas de dados dos periódicos, sinalizando o número de vezes que dois termos ocorrem juntos (REDEKER et al., 2019). Para a formação do mapa, todos os strings de busca (palavras chaves utilizadas na base de dados para encontrar artigos do tema) foram 
considerados simultaneamente, nas duas bases de dados consultadas, sem aplicação de filtros e com ocorrência mínima de 5 vezes para cada palavra.

Em seguida ao mapeamento dos subtemas, os strings de busca foram usados separadamente e, dado o material disponível, foram aplicados os critérios de inclusão e exclusão. Os critérios de inclusão foram: a) ser um material qualificado como artigo acadêmico. Essa escolha é porque o material artigo é mais robusto $\mathrm{e}$ revisado. Por outro lado, os critérios de exclusão são consistentes com: a) qualquer material que não seja classificado como artigo acadêmico (livros, artigos de conferência, notas e resenhas), b) materiais duplicados nas bases de dados Web of Science e
Scopus, c) não estar no idioma inglês (linguagem universal); d) não disponibilizar integralmente o material para leitura; e) não estar relacionado ao tema da inovação aberta na agricultura; f) não pertencer ao período de análise dos últimos dez anos completos (20102019); e g) materiais com menos de 5 citações no momento da coleta dos artigos (primeira semana de agosto/2020).

Após a aplicação dos filtros, os demais artigos foram lidos na íntegra, classificados e codificados, conforme metodologia apresentada em Jabbour (2013); Govindan et al. (2015); e Amui et al. (2017). O Quadro 1 representa o sistema de classificação dos periódicos coletados. 
Quadro 1: Sistema de classificação dos artigos coletados.

\begin{tabular}{|c|c|c|}
\hline \multicolumn{3}{|c|}{ SISTEMA DE CLASSIFICAÇÃO } \\
\hline \multirow{3}{*}{ Contexto } & Países desenvolvidos & $1 \mathrm{~A}$ \\
\hline & Países em desenvolvimento & 1B \\
\hline & Não se aplica & $1 \mathrm{C}$ \\
\hline \multirow{2}{*}{ Foco } & Open Innovation como principal tema & $2 \mathrm{~A}$ \\
\hline & Open Innovation como suporte à teoria & $2 \mathrm{~B}$ \\
\hline \multirow{6}{*}{ Método de pesquisa } & Qualitativa & $3 \mathrm{~A}$ \\
\hline & Quantitativa & $3 \mathrm{~B}$ \\
\hline & Teórica & $3 \mathrm{C}$ \\
\hline & Empírica & $3 \mathrm{D}$ \\
\hline & Estudos de casos & $3 \mathrm{E}$ \\
\hline & Survey & $3 \mathrm{~F}$ \\
\hline \multirow{5}{*}{ Segmento } & Agricultura e pecuária & $4 \mathrm{~A}$ \\
\hline & Caça e pesca & $4 \mathrm{~B}$ \\
\hline & Mineração & $4 \mathrm{C}$ \\
\hline & Extrativismo vegetal & $4 \mathrm{D}$ \\
\hline & Não se aplica & $4 \mathrm{E}$ \\
\hline \multirow{5}{*}{ Agentes } & Produtores & $5 \mathrm{~A}$ \\
\hline & Agroindústrias & $5 B$ \\
\hline & Distribuidores & $5 \mathrm{C}$ \\
\hline & Governos & $5 \mathrm{D}$ \\
\hline & Não se aplica & $5 \mathrm{E}$ \\
\hline \multirow{6}{*}{ Nacionalidade dos agentes } & América & $6 \mathrm{~A}$ \\
\hline & Europa & $6 B$ \\
\hline & Ásia & $6 \mathrm{C}$ \\
\hline & África & $6 \mathrm{D}$ \\
\hline & Oceania & $6 \mathrm{E}$ \\
\hline & Não se aplica & $6 \mathrm{~F}$ \\
\hline \multirow{5}{*}{ Tipo de Inovação } & Produto & $7 \mathrm{~A}$ \\
\hline & Processo & $7 \mathrm{~B}$ \\
\hline & Organizacional & $7 \mathrm{C}$ \\
\hline & Marketing & $7 \mathrm{D}$ \\
\hline & Não se aplica & $7 \mathrm{E}$ \\
\hline
\end{tabular}

Fonte: Adaptado de Jabbour (2013); Govindan et al. (2015); Amui et al. (2017).

O resumo da contribuição de cada artigo, a descrição dos pontos de pesquisas futuras, a classificação dos

\section{RESULTADOS E DISCUSSÃO}

\section{Estudo de palavras chaves}

O VOSviewer gera um mapa visual, onde quanto maior o nível de materiais, e o estudo de palavras chaves são apresentados na próxima seção.

ocorrência das palavras-chaves, a forma da palavra é mais densa (LAWAL et al., 2019). Assim, a Figura 1 possui 5 clusters a serem investigados. $\mathrm{O}$ primeiro (em vermelho) envolve as 
palavras-chaves mudança climática, inovação colaborativa, comércio, pesquisa em engenharia, gestão industrial, propriedade intelectual, patentes e invenções, pesquisa e desenvolvimento e transferência de tecnologia. O segundo (em verde) tem as palavras agricultura, inovação, inovação de processos, conhecimento, sistema baseado em conhecimento, laboratório vivo e sustentabilidade. O terceiro (em azul) trata das palavras competição, empreendedorismo, gestão do conhecimento, inovação aberta e pequenas e médias empresas. O quarto (em amarelo) apresenta as palavras humano, indústria, desenvolvimento de novos produtos, desenvolvimento de produto, e o último cluster (em lilás), relata as palavras China e indústria alimentícia. Todas as palavras-chaves representam os estudos desenvolvidos pela literatura, no contexto da inovação aberta na agricultura mundial, no entanto, apenas o cluster 3 menciona especificamente a palavra inovação aberta, o foco deste artigo. Nesse cluster, é possível visualizar as práticas de gestão do conhecimento, empreendedorismo, e pequenas e médias empresas, que podem ter pesquisas desenvolvidas, principalmente, para atingir os agentes agrícolas de menor porte, como os inseridos em economias agrícolas de pequena escala e familiares.

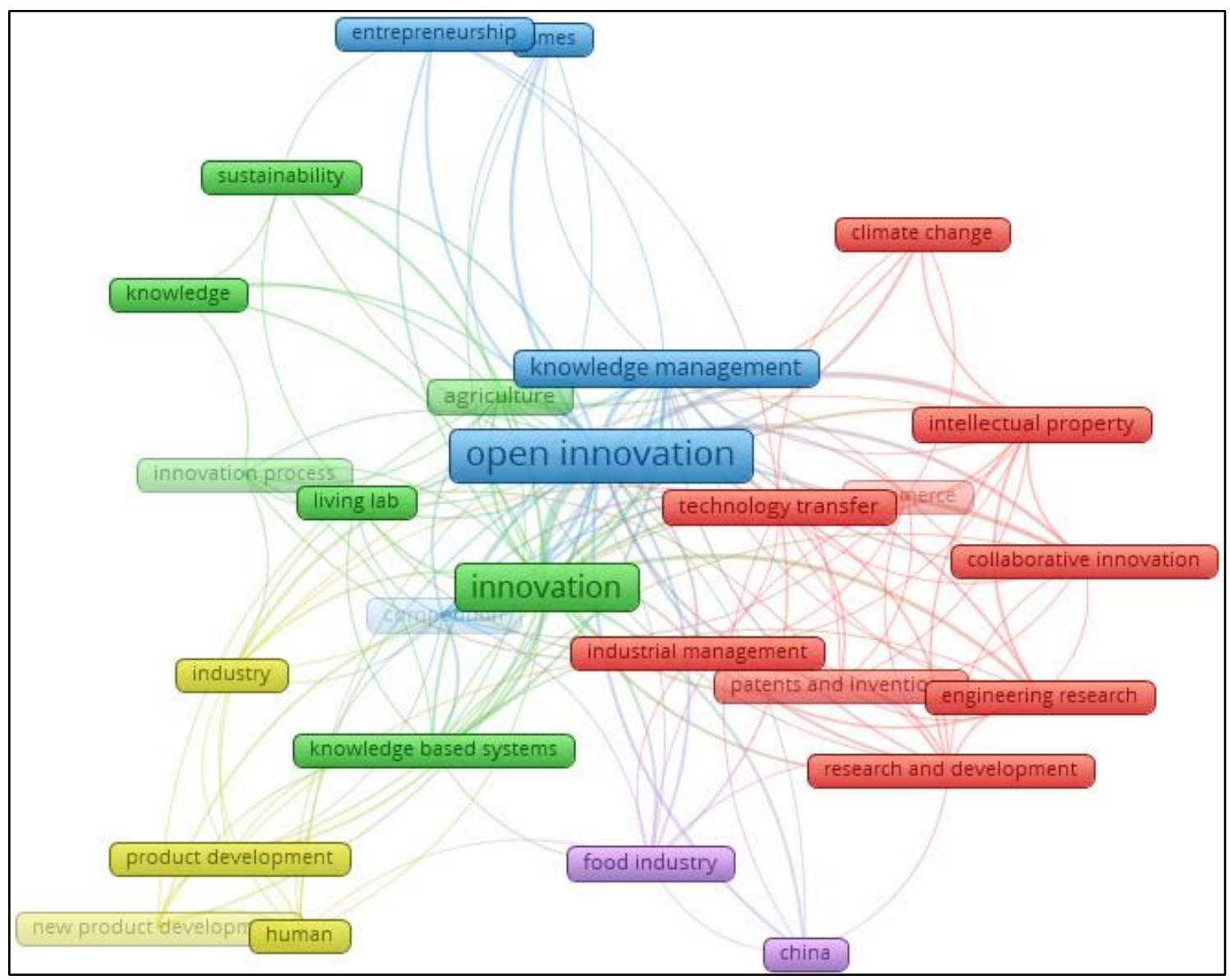

Figura 1: Mapa de ocorrência de palavras chaves (VOSviewer)

Paralelamente, a palavra inovação foi mencionada no cluster 2 , juntamente com agricultura, inovação de processos, conhecimento e sistemas baseado em conhecimento. Nesse aspecto há uma perspectiva para pesquisas futuras, pois os pesquisadores podem direcionar esforços sobre como a 
gestão do conhecimento permitirá romper as barreiras da inovação aberta para as agroindústrias. Investigações sobre a formação da rede e parcerias ideais, envolvendo a participação de governos e, pesquisas para conscientizar os produtores rurais a apoiar a inovação aberta são outras possibilidades de estudo.
O estudo de palavras-chave identificou os temas da literatura com maior volume de estudos os quais podem ser ampliados sob a perspectiva de diferentes teorias e aspectos, bem como aqueles com menor representação, que precisam ser explorados e são oportunidades para futuras pesquisas (Quadro 2).

Quadro 2: Nível de ocorrência e força das palavras chaves.

\begin{tabular}{|c|c|c|c|}
\hline \multirow{4}{*}{$\begin{array}{c}\text { ESTUDOS PARA } \\
\text { SEREM }\end{array}$} & PALAVRA CHAVE & OCORRENCIA & FORÇA TOTAL DO LINK \\
\cline { 2 - 4 } EXPANDIDODS SOB & Inovação aberta & 77 & 121 \\
\cline { 2 - 4 } OUTRAS & Inovação & 43 & 92 \\
\cline { 2 - 4 } PERSPECTIVAS & Gestão do conhecimento & 11 & 38 \\
\cline { 2 - 4 } & Transferência de tecnologia & 10 & 32 \\
\cline { 2 - 4 } & Competição & 10 & 30 \\
\cline { 2 - 4 } & Propriedade intelectual & 8 & 29 \\
\cline { 2 - 4 } & Agricultura & 5 & 25 \\
\cline { 2 - 4 } & Inovação de processos & 5 & 9 \\
\cline { 2 - 4 } & Empreendedorismo & 5 & 10 \\
\cline { 2 - 4 } OPORTUNIDADES & Mudança climática & 6 & 10 \\
\cline { 2 - 4 } DE PESQUISA & Capital humano & 5 & 10 \\
\cline { 2 - 4 } & Desenvolvimento de novos produtos & 5 & 10 \\
\cline { 2 - 4 } & Pequenas e médias empresas & 5 & 11 \\
\cline { 2 - 4 } & Sustentabilidade & 5 & \\
\hline
\end{tabular}

Fonte: Elaborado pelos autores.

Sob a perspectiva da teoria baseada em recursos, teoria ator-rede, teoria da difusão da inovação, visão baseada no conhecimento, teoria da gestão do conhecimento e teoria das partes interessadas (FIORINI et al., 2018), estudar a inovação aberta na agricultura são sugestivos para se expandir a literatura com o maior número de ocorrências (número de links de um item com outros itens) e nível de força (força total das ligações de um item com outros itens). Da mesma forma, o enquadramento da inovação aberta no contexto da quarta revolução industrial é outra perspectiva para aumentar a pesquisa atual.

Pode-se observar no Quadro 2 que, para que a inovação aberta se torne realidade na agricultura global, são necessários um maior volume de estudos voltados para a inovação de processos, especificamente para mitigar os efeitos da mudança climática e melhorar a sustentabilidade; fatores estes de enorme importância deste século XXI e de aderência aos objetivos de desenvolvimento sustentável da Organização das Nações Unidas. Também é necessária pesquisa adicional para desenvolver o empreendedorismo do capital humano para formar vínculos de parceria entre universidades e outros agentes. Concentrar-se em estudos de inovação aberta em pequenas e médias empresas atuantes na produção de alimentos seria uma solução para lidar com o problema da segurança alimentar, ocasionado pelo aumento do volume populacional, uma das preocupações levantadas pela Organização das Nações Unidas para Alimentação e Agricultura (FAO) (FAO, 2020).

\section{Estudo da classificação dos artigos}

Com os strings de busca foram identificados 250 materiais disponíveis e, posteriormente, aplicou-se o critério de inclusão, obtendo um resultado de 
146. Para alcançar esse resultado foram excluídas publicações em livros e capítulos, artigos de conferências, resenhas de conferências, entre outros.

Nos 146 artigos incluídos na análise foi aplicado o critério de exclusão para eliminar artigos duplicados nas duas bases de dados, ou seja, foram cortados 36 artigos do estudo, restando 110 artigos. Desses, 2 foram excluídos por serem uma série de livros, 3 por não estarem em inglês (linguagem universal), 23 por não pertencerem ao período de análise deste artigo (últimos dez anos completos), 8 por não oferecerem o artigo integralmente para a leitura e 35 por terem menos de 5 citações no momento da coleta dos artigos (primeira semana de agosto/2020). Os 39 artigos restantes foram lidos na íntegra e 11 foram descartados por não tratarem da temática inovação aberta na agricultura (abordava outros assuntos). A amostra dos artigos finais, após aplicação dos critérios de inclusão e exclusão, foi de 28 periódicos.

Ao ler os periódicos selecionados, os artigos foram classificados por volume de citações, e o nome do artigo, autores, título do jornal e ano de publicação foram coletados.
O Quadro 3 destaca a revista "British Food Journal" como a mais frequente na amostra de periódicos, e o artigo "Organisational modes for Open Innovation in the bio-pharmaceutical industry: An exploratory analysis", com o maior volume de citações.
A revista "Technological Forecasting and Social Change" possui o melhor fator de impacto (5.846). Em geral, verificou-se na amostra de artigos que eles não estão concentrados em um tipo de periódico, e que o volume de citação é diversificado (não uniforme ou com um padrão de tendência).

Percebe-se que a literatura procura apresentar como a inovação aberta permeia os agentes agrícolas e explica situações / diretrizes sobre como o conhecimento externo pode ser útil para obter produtos e processos inovadores. A noção de explorar conhecimento e informação, proveniente de fontes externas, é sustentada por Robertson et al. (2012), visto que o conhecimento transcende os limites organizacionais, envolve os atores da empresa e expande a capacidade de criação.

Os principais pontos de cada artigo estudado e a indicação de pesquisas futuras sugeridas pela literatura estão apresentados na Quadro 3. 
Quadro 3: Pontos principais dos artigos coletados e indicação de pesquisas futuras.

\begin{tabular}{|c|c|c|c|c|c|c|}
\hline RANK & CITAÇÃO & ARTIGO & AUTOR & PERIÓDICO & PONTOS PRINCIPAIS & PESQUISAS FUTURAS \\
\hline 1 & 241 & $\begin{array}{l}\text { Organisational modes for } \\
\text { Open Innovation in the bio- } \\
\text { pharmaceutical industry: An } \\
\text { exploratory analysis }\end{array}$ & $\begin{array}{l}\text { Bianchi et al. } \\
\quad(2011)\end{array}$ & Technovation & $\begin{array}{l}\text { Investiga a adoção da inovação aberta na indústria bio } \\
\text { farmacêutica, estudando em quais modalidades } \\
\text { organizacionais ela é posta em prática, e como essas } \\
\text { modalidades se entrelaçam com as diferentes fases do } \\
\text { processo de descoberta e desenvolvimento de } \\
\text { medicamentos. } \\
\end{array}$ & $\begin{array}{c}\text { Investigar variáveis que } \\
\text { determinaram a evolução } \\
\text { temporal nos modos de } \\
\text { organização da inovação aberta } \\
\text { e ampliação da composição da } \\
\text { amostra. } \\
\end{array}$ \\
\hline 2 & 84 & $\begin{array}{l}\text { Organizing information } \\
\text { integration in an agri-food-A } \\
\text { method based on a service- } \\
\text { oriented architecture and } \\
\quad \text { living lab approach }\end{array}$ & $\begin{array}{l}\text { Wolfert et al. } \\
\quad(2010)\end{array}$ & $\begin{array}{l}\text { Computers and } \\
\text { Electronics in } \\
\text { Agriculture }\end{array}$ & $\begin{array}{l}\text { Trabalha com o Living Lab (LL) para promover a } \\
\text { inovação proativa na qual os usuários são co-criadores } \\
\text { de produtos e serviços, onde todos os atores conhecem } \\
\text { e cooperam em torno de tópicos de integração de } \\
\text { informações. Para o processo de inovação aberta, } \\
\text { agricultores, empresas e governo têm problemas } \\
\text { práticos que são resolvidos com novos modelos de } \\
\text { conhecimento. }\end{array}$ & $\begin{array}{l}\text { Estender o LL para outros } \\
\text { contextos de aplicação e } \\
\text { enriquecer o método. }\end{array}$ \\
\hline 3 & 82 & $\begin{array}{l}\text { Finding the right partners: } \\
\text { Institutional and personal } \\
\text { modes of governance of } \\
\text { university-industry } \\
\quad \text { interactions }\end{array}$ & $\begin{array}{l}\text { Bodas Freitas } \\
\text { et al. (2013) }\end{array}$ & Research Policy & $\begin{array}{l}\text { Estuda dois modos diferentes de governança de } \\
\text { interações universidade-indústria: modo institucional, } \\
\text { interações mediadas pela universidade por meio de suas } \\
\text { estruturas administrativas, e modo contratual pessoal, } \\
\text { interações envolvem formal e vinculativo acordos } \\
\text { contratuais entre firmas e acadêmicos individuais, } \\
\text { realizados sem o envolvimento direto da universidade. }\end{array}$ & $\begin{array}{l}\text { Examinar a integração das } \\
\text { diferentes formas de interação } \\
\text { com a pesquisa universitária. }\end{array}$ \\
\hline 4 & 63 & $\begin{array}{l}\text { Open innovation and new } \\
\text { issues in } R \& D \text { organization } \\
\text { and personnel management }\end{array}$ & $\begin{array}{l}\text { Petroni et al. } \\
\quad(2011)\end{array}$ & \begin{tabular}{|} 
International \\
Journal of \\
Human Resource \\
Management
\end{tabular} & $\begin{array}{l}\text { Investiga como a adoção da inovação mudou as } \\
\text { estruturas organizacionais de P\&D e alterou os métodos } \\
\text { da gestão pessoal, concentrando-se na identificação e } \\
\text { análise do novo perfil profissional e funções que } \\
\text { surgiram nos laboratórios de } P \& D \text {, como resultado da } \\
\text { adoção de práticas de inovação aberta. }\end{array}$ & Sem indicação. \\
\hline 5 & 56 & $\begin{array}{l}\text { Designing coupled } \\
\text { innovations for the } \\
\text { sustainability transition of } \\
\text { agrifood systems }\end{array}$ & $\begin{array}{l}\text { Meynard et } \\
\text { al. (2017) }\end{array}$ & $\begin{array}{c}\text { Agricultural } \\
\text { Systems }\end{array}$ & $\begin{array}{l}\text { A necessidade de inovação nos sistemas } \\
\text { agroalimentares requer ir além da histórica } \\
\text { especialização de competências e das formas usuais de } \\
\text { coordenação entre projetistas, uma vez que uma } \\
\text { abordagem integrada do design na agricultura e na }\end{array}$ & \begin{tabular}{|} 
Responder às questões de \\
pesquisa apresentadas no artigo, \\
dentre as quais: Como deve ser \\
composta a mesa de atores \\
envolvidos no processo de \\
\end{tabular} \\
\hline
\end{tabular}




\begin{tabular}{|c|c|c|c|c|c|c|}
\hline & & & & & $\begin{array}{l}\text { alimentação, levando em consideração todo o sistema } \\
\text { agroalimentar, é necessária. }\end{array}$ & $\begin{array}{l}\text { design? Que política pública } \\
\text { potencializaria as inovações } \\
\text { associadas? Como abrir a } \\
\text { política agrícola e alimentar? }\end{array}$ \\
\hline 6 & 50 & $\begin{array}{l}\text { Network embeddedness and } \\
\text { new product development in } \\
\text { the biopharmaceutical } \\
\text { industry: The moderating role } \\
\text { of open innovation flow }\end{array}$ & $\begin{array}{l}\text { Mazzola et al. } \\
\quad(2015)\end{array}$ & $\begin{array}{l}\text { International } \\
\text { Journal of } \\
\text { Production } \\
\text { Economics }\end{array}$ & $\begin{array}{l}\text { Argumenta-se que as posições de rede fornecem o } \\
\text { conteúdo da informação à empresa, enquanto o fluxo de } \\
\text { inovação aberto descreve como a empresa usa esse } \\
\text { conteúdo, portanto, a combinação desses dois conceitos } \\
\text { tem um impacto significativo no desenvolvimento de } \\
\text { novos produtos. Estar localizado centralmente na rede } \\
\text { afeta positivamente o processo de desenvolvimento de } \\
\text { novos produtos, enquanto ter uma posição de furos } \\
\text { estruturais não tem efeito sobre o desempenho. } \\
\end{array}$ & $\begin{array}{l}\text { Validar a medida de inovação } \\
\text { aberta criada no artigo e } \\
\text { abordar a dimensão "imersão } \\
\text { relacional" (nível de } \\
\text { relacionamento), } \\
\text { desconsiderada no periódico. }\end{array}$ \\
\hline 7 & 42 & $\begin{array}{l}\text { Achievements and challenges } \\
\text { of innovation co-production } \\
\text { support initiatives in the } \\
\text { Australian and Dutch dairy } \\
\text { sectors: A comparative study }\end{array}$ & $\begin{array}{l}\text { Klerkx \& } \\
\text { Nettle (2013) }\end{array}$ & Food Policy & $\begin{array}{c}\text { Analisa, comparativamente, projetos de inovação do } \\
\text { setor de laticínios na Holanda e da Austrália, } \\
\text { concluindo que as políticas de inovação do setor devem } \\
\text { abordar as restrições institucionais, reconhecer que a } \\
\text { facilitação da coprodução de inovação precisa de } \\
\text { recursos adequados, aumentar o apoio para } \\
\text { coordenação de iniciativas para evitar a duplicação de } \\
\text { esforços e levar em consideração o ambiente } \\
\text { institucional específico de países e setores para orientar } \\
\text { o projeto de co-inovação. }\end{array}$ & $\begin{array}{l}\text { Documentar, compreender e } \\
\text { medir o impacto das iniciativas } \\
\text { de apoio à coprodução da } \\
\text { inovação em vários contextos. }\end{array}$ \\
\hline 8 & 32 & $\begin{array}{c}\text { Open innovation and } \\
\text { company culture: Internal } \\
\text { openness makes the difference }\end{array}$ & $\begin{array}{l}\text { Kratzer et al } \\
\quad(2017)\end{array}$ & $\begin{array}{l}\text { Technological } \\
\text { Forecasting and } \\
\text { Social Change }\end{array}$ & $\begin{array}{l}\text { A inovação é realizada em um ambiente institucional } \\
\text { caracterizado por regras e regulamentos que podem } \\
\text { apoiar ou impedir a inovação. O artigo comenta que a } \\
\text { cultura de inovação da empresa vem em cinco formas } \\
\text { principais: inovação fechada; fazer, usar, interagir; } \\
\text { terceirização de capacidades de inovação; inovação } \\
\text { extramural, e inovação proativa. }\end{array}$ & $\begin{array}{l}\text { Propõe que seja feito um } \\
\text { trabalho conceitual e empírico } \\
\text { que elabore os elementos e } \\
\text { visões sobre a cultura de } \\
\text { inovação da empresa, a abertura } \\
\text { interna à inovação e as } \\
\text { respectivas questôes de gestão. }\end{array}$ \\
\hline 9 & 30 & $\begin{array}{l}\text { The interaction between inter- } \\
\text { firm and interlocking } \\
\text { directorate networks on firm's } \\
\text { new product development } \\
\text { outcomes }\end{array}$ & $\begin{array}{l}\text { Mazzola et al. } \\
\quad(2016)\end{array}$ & $\begin{array}{l}\text { Journal of } \\
\text { Business } \\
\text { Research }\end{array}$ & $\begin{array}{c}\text { Explora a interação entre um conselho de administração } \\
\text { proeminente e a rede de relacionamentos entre } \\
\text { empresas no desenvolvimento de novos produtos da } \\
\text { indústria bio farmacêutica. }\end{array}$ & $\begin{array}{l}\text { Analisar interações entre redes } \\
\text { interfirmas e interpessoais, } \\
\text { avaliando o papel moderador da } \\
\text { rede de cada diretor no } \\
\text { desempenho inovador. }\end{array}$ \\
\hline
\end{tabular}




\begin{tabular}{|c|c|c|c|c|c|c|}
\hline 10 & 29 & $\begin{array}{l}\text { Development of small and } \\
\text { medium-sized enterprise } \\
\text { horizontal innovation } \\
\text { networks: UK agri-food } \\
\text { sector study }\end{array}$ & $\begin{array}{l}\text { McAdam et } \\
\text { al. (2014) }\end{array}$ & \begin{tabular}{|c|} 
International \\
Small Business \\
$\quad$ Journal: \\
Researching \\
Entrepreneurship \\
\end{tabular} & $\begin{array}{c}\text { Discute a colaboração horizontal entre pequenas e } \\
\text { médias empresas, e quais rivalidades individuais são } \\
\text { superadas pela necessidade da inovação. Explora o } \\
\text { desenvolvimento de redes de inovação horizontal } \\
\text { dentro de uma rede de padeiros artesanais do Reino } \\
\text { Unido. }\end{array}$ & $\begin{array}{l}\text { Usar o modelo conceitual } \\
\text { proposto como estrutura para } \\
\quad \text { explorar a colaboração } \\
\text { horizontal em outros setores. }\end{array}$ \\
\hline 11 & 22 & $\begin{array}{l}\text { Keeping your secrets public? } \\
\text { Open versus closed } \\
\text { innovation processes in the } \\
\text { Hungarian wine sector }\end{array}$ & $\begin{array}{l}\text { Dries et al. } \\
\text { (2014) }\end{array}$ & $\begin{array}{l}\text { International } \\
\text { Food and } \\
\text { Agribusiness } \\
\text { Management } \\
\quad \text { Review }\end{array}$ & $\begin{array}{c}\text { O tema visa responder como organizar laços externos } \\
\text { sem comprometer o conhecimento e os ativos, } \\
\text { entendendo os principais fatores que levam as empresas } \\
\text { de vinho a adotarem um sistema aberto de inovação. } \\
\text { Como resultado, identificou-se que as empresas de } \\
\text { vinho húngaras têm maior probabilidade de usar ideias } \\
\text { externas nas fases de geração e desenvolvimento de } \\
\text { ideias do que na fase de comercialização. }\end{array}$ & $\begin{array}{l}\text { Repetir a pesquisa levando em } \\
\text { consideração as diferenças } \\
\text { regionais entre as organizações } \\
\text { estudadas. }\end{array}$ \\
\hline 12 & 22 & $\begin{array}{l}\text { University knowledge, open } \\
\text { innovation and technological } \\
\text { capital in Spanish science } \\
\text { parks: Research revealing or } \\
\text { technology selling? }\end{array}$ & $\begin{array}{l}\text { Villasalero } \\
\text { (2014) }\end{array}$ & $\begin{array}{l}\text { Journal of } \\
\text { Intellectual } \\
\text { Capital }\end{array}$ & $\begin{array}{c}\text { Investigar a conexão entre a pesquisa universitária e o } \\
\text { capital tecnológico desenvolvido por empresas de } \\
\text { parque científico. O conhecimento científico produzido } \\
\text { pelas universidades contribui principalmente para o } \\
\text { setor privado de base tecnológica. }\end{array}$ & $\begin{array}{c}\text { Buscar comparações de vários } \\
\text { países, a fim de saber se a } \\
\text { transferência de tecnologia é } \\
\text { condicionada pelos recursos de } \\
\text { cada país. }\end{array}$ \\
\hline 13 & 21 & $\begin{array}{c}\text { Better practices for managing } \\
\text { intellectual assets in } \\
\text { collaborations }\end{array}$ & $\begin{array}{l}\text { Mehlman } \\
\text { (2010) }\end{array}$ & $\begin{array}{c}\text { Research } \\
\text { Technology } \\
\text { Management }\end{array}$ & $\begin{array}{l}\text { Explora o tema de questões intelectuais de ativos em } \\
\text { inovação aberta. A gestão deve incorporar inovação } \\
\text { externa ao sistema de desenvolvimento de novos } \\
\text { produtos e garantir que a recompensa incentive uma } \\
\text { abordagem "inventado em qualquer lugar". }\end{array}$ & Sem indicação. \\
\hline 14 & 16 & $\begin{array}{c}\text { Open Innovation: A Case- } \\
\text { study of the Hungarian Wine } \\
\text { Sector }\end{array}$ & $\begin{array}{l}\text { Dries et al. } \\
\text { (2013) }\end{array}$ & EuroChoices & $\begin{array}{l}\text { Levanta a questão de como arranjar laços externos sem } \\
\text { comprometer o conhecimento e ativos único. Isso é } \\
\text { particularmente polêmico no setor vitivinícola, onde } \\
\text { estratégias de marketing inovadoras devem ser } \\
\text { combinadas com receitas exclusivas e secretas. }\end{array}$ & Sem indicação. \\
\hline 15 & 15 & $\begin{array}{c}\text { Knowledge management and } \\
\text { open innovation in agri-food } \\
\text { crowdfunding }\end{array}$ & Cillo (2019) & $\begin{array}{c}\text { British Food } \\
\text { Journal }\end{array}$ & $\begin{array}{l}\text { Analisa a relação entre a capacidade da gestão do } \\
\text { conhecimento e inovação aberta de sucesso nas } \\
\text { empresas agroalimentares, investigando a importância } \\
\text { da exploração do conhecimento baseado em TI, } \\
\text { capacidades no sucesso da estratégia de inovação } \\
\text { aberta, e o papel mediador do conhecimento. }\end{array}$ & $\begin{array}{l}\text { Entender melhor a inovação } \\
\text { aberta no setor de alimentos, } \\
\text { com a execução de estudos de } \\
\text { caso mais focados e mais } \\
\text { empíricos, empregando } \\
\text { crowdfunding em sua análise. }\end{array}$ \\
\hline
\end{tabular}




\begin{tabular}{|c|c|c|c|c|c|c|}
\hline 16 & 14 & $\begin{array}{l}\text { Developing new technology } \\
\text { platforms for new business } \\
\text { models: Syngenta's } \\
\text { partnership with the } \\
\text { University of Manchester }\end{array}$ & $\begin{array}{l}\text { Malik et al. } \\
\text { (2011) }\end{array}$ & $\begin{array}{l}\text { Research- } \\
\text { Technology } \\
\text { Management }\end{array}$ & $\begin{array}{c}\text { Estabelece uma parceria estratégica entre a empresa } \\
\text { Syngenta e a Universidade de Manchester, para criar } \\
\text { um Centro de Inovação da Universidade, focado na } \\
\text { introdução de tecnologia de sensores e plataformas de } \\
\text { computação na agricultura (agroeletrônica). Sensores } \\
\text { baseados em abordagens para apoiar a agricultura, } \\
\text { novas tecnologias de detecção, identificação por } \\
\text { radiofrequência (RFID), redes de sensores sem fio, } \\
\text { coleta de energia e gerenciamento de informações, e } \\
\text { conhecimento são temas dessa parceria. }\end{array}$ & $\begin{array}{l}\text { Observar se outras empresas de } \\
\text { base tecnológica enfrentam } \\
\text { desafios para o negócio } \\
\text { principal, estabelecendo um } \\
\text { caminho para formar alianças } \\
\text { estratégicas. }\end{array}$ \\
\hline 17 & 14 & $\begin{array}{l}\text { How is innovation in } \\
\text { aquaculture conceptualized } \\
\text { and managed? A systematic } \\
\text { literature review and } \\
\text { reflection framework to } \\
\text { inform analysis and action }\end{array}$ & $\begin{array}{c}\text { Joffre et al. } \\
\quad(2017)\end{array}$ & Aquaculture & $\begin{array}{l}\text { Usando uma lente analítica derivada da literatura, } \\
\text { (voltada para a tecnologia, sistêmica e negócios e } \\
\text { abordagens gerenciais para a inovação) analisa } \\
\text { sistematicamente as abordagens à inovação usadas no } \\
\text { desenvolvimento da aquicultura. }\end{array}$ & $\begin{array}{l}\text { Considerar as dimensões } \\
\text { sociais, ecológicas e } \\
\text { institucionais da inovação na } \\
\text { aquicultura. Abordagens } \\
\text { semelhantes são necessárias na } \\
\text { África, América Latina ou } \\
\text { países do Sudeste Asiático. }\end{array}$ \\
\hline 18 & 13 & $\begin{array}{l}\text { Integrating the management } \\
\text { of socio-ethical factors into } \\
\text { industry innovation: towards } \\
\text { a concept of Open } \\
\text { Innovation } 2.0\end{array}$ & $\begin{array}{l}\text { Long \& Blok } \\
\quad \text { (2018) }\end{array}$ & $\begin{array}{l}\text { International } \\
\text { Food and } \\
\text { Agribusiness } \\
\text { Management } \\
\quad \text { Review }\end{array}$ & $\begin{array}{l}\text { Objetiva estudar se a inovação aberta se sobrepõe à } \\
\text { inovação responsável. Esse modelo de sobreposição foi } \\
\text { aplicado na Europa, que desenvolve inovação para uma } \\
\text { agricultura inteligente em termos de clima, produzindo } \\
\text { mais alimentos com redução de gases de efeito estufa e } \\
\text { impactos climáticos. Há compatibilidade entre inovação } \\
\text { aberta e inovação responsável. }\end{array}$ & $\begin{array}{l}\text { Testar empiricamente a } \\
\text { estrutura de integração entre } \\
\text { inovação aberta e inovação } \\
\text { responsável proposta no artigo. }\end{array}$ \\
\hline 19 & 13 & $\begin{array}{l}\text { Building sustainable } \\
\text { development through } \\
\text { technology transfer in a } \\
\text { Romanian university }\end{array}$ & $\begin{array}{l}\text { Vac \& Fitiu } \\
\quad(2017)\end{array}$ & $\begin{array}{l}\text { Sustainability } \\
\text { (Switzerland) }\end{array}$ & \begin{tabular}{|l} 
Analisa as atividades do escritório de transferência de \\
tecnologia para apoiar os resultados de pesquisa em \\
comercialização no contexto da Universidade de \\
Ciências Agrárias e Medicina Veterinária da Romênia. \\
Os escritórios dentro de uma universidade é uma \\
oportunidade real, tanto na perspectiva de uma \\
alternativa de financiamento à pesquisa, educação, \\
alfabetização ou empreendedorismo. \\
\end{tabular} & Sem indicação. \\
\hline 20 & 10 & $\begin{array}{l}\text { Application and evaluation of } \\
\text { a participatory "open } \\
\text { innovation" approach } \\
\text { (ROIR): The case of }\end{array}$ & $\begin{array}{l}\text { Specht et al. } \\
\text { (2016) }\end{array}$ & $\begin{array}{l}\text { Landscape and } \\
\text { Urban Planning }\end{array}$ & $\begin{array}{c}\text { Avalia uma abordagem participativa de inovação aberta } \\
\text { (ROIR), cujo objetivo é reunir as partes interessadas } \\
\text { para desenvolver inovações regionais na agricultura } \\
\text { urbana de Berlim. As inovações estão focadas na }\end{array}$ & $\begin{array}{l}\text { O ROIR deve ser testado e } \\
\text { avaliado para aumentar seu } \\
\text { potencial para a futura criação } \\
\text { participativa de inovações em }\end{array}$ \\
\hline
\end{tabular}




\begin{tabular}{|c|c|c|c|c|c|c|}
\hline & & $\begin{array}{l}\text { introducing zero-acreage } \\
\quad \text { farming in Berlin }\end{array}$ & & & $\begin{array}{l}\text { agricultura de área zero para produção de alimentos, } \\
\text { com base nos termos de (1) geração de conhecimento, } \\
\text { (2) formação de redes, (3) implementação de novos } \\
\text { projetos e (4) percepção geral do ROIR. A inovação } \\
\text { ocorreu em redes colaborativas, nas quais as } \\
\text { informações são trocadas e ocorrem nos processos de } \\
\text { aprendizagem. }\end{array}$ & ambientes rurais e urbanos. \\
\hline 21 & 10 & $\begin{array}{l}\text { A method using two } \\
\text { dimensions of the patent } \\
\text { classification for measuring } \\
\text { the technological proximity: } \\
\text { an application in identifying a } \\
\text { potential } R \& D \text { partner in } \\
\text { biotechnology }\end{array}$ & $\begin{array}{l}\text { Angue et al. } \\
\text { (2014) }\end{array}$ & $\begin{array}{c}\text { Journal of } \\
\text { Technology } \\
\text { Transfer }\end{array}$ & $\begin{array}{l}\text { Mostra como informações contidas em documentos de } \\
\text { patentes pode ser usada para identificar proximidades } \\
\text { tecnológicas básicas e específicas entre empresas, e } \\
\text { portanto, um parceiro potencial de pesquisa e } \\
\text { desenvolvimento. }\end{array}$ & $\begin{array}{l}\text { Melhorar o método e lidar com } \\
\text { as limitações do artigo, } \\
\text { aumentar a amostra do estudo, } \\
\text { testar a robustez das medidas } \\
\text { em outras indústrias e setores, e } \\
\text { reproduzir a análise usando a } \\
\text { nova classificação da European } \\
\text { Patent Office. }\end{array}$ \\
\hline 22 & 8 & $\begin{array}{l}\text { Patents and the practice of } \\
\text { open science among } \\
\text { government research } \\
\text { institutes in Malaysia: The } \\
\text { case of Malaysian Rubber } \\
\text { Board }\end{array}$ & $\begin{array}{c}\text { Azmi \& } \\
\text { Alavi (2013) }\end{array}$ & $\begin{array}{l}\text { World Patent } \\
\text { Information }\end{array}$ & $\begin{array}{l}\text { Examina as preocupações centrais em torno da ciência } \\
\text { aberta em institutos de pesquisa em relação ao resultado } \\
\text { de P\&D financiado pelo governo da Malásia, } \\
\text { abordando como os institutos de pesquisa } \\
\text { governamental decidem quais inovações agrícolas } \\
\text { devem ser disponibilizadas no domínio público e quais } \\
\text { devem ser patenteadas e disponibilizadas por uma taxa. }\end{array}$ & Sem indicação. \\
\hline 23 & 7 & $\begin{array}{l}\text { How different agricultural } \\
\text { research models contribute to } \\
\text { impacts: Evidence from } 13 \\
\text { case studies in developing } \\
\text { countries }\end{array}$ & $\begin{array}{l}\text { Faure et al. } \\
\text { (2018) }\end{array}$ & $\begin{array}{l}\text { Agricultural } \\
\text { Systems }\end{array}$ & $\begin{array}{c}\text { Apresenta os achados da aplicação de uma metodologia } \\
\text { participativa de avaliação de impacto desenvolvida pelo } \\
\text { Centro Francês de Pesquisa Agropecuária para o } \\
\text { Desenvolvimento Internacional (CIRAD), } \\
\text { representando diferentes processos de inovação na } \\
\text { pesquisa agrícola para o desenvolvimento. }\end{array}$ & $\begin{array}{l}\text { Compreender quando e como as } \\
\text { equipes de pesquisa devem } \\
\text { cumprir suas funções e repensar } \\
\text { a gestão da pesquisa quando o } \\
\text { financiamento é baseado em } \\
\text { projetos. }\end{array}$ \\
\hline 24 & 7 & $\begin{array}{l}\text { Stakeholder roles for fostering } \\
\text { ambidexterity in Sub-Saharan } \\
\text { African agricultural netchains } \\
\text { for the emergence of multi- } \\
\text { stakeholder cooperatives }\end{array}$ & $\begin{array}{l}\text { Pérez } \\
\text { Perdomo et } \\
\text { al. (2016) }\end{array}$ & $\begin{array}{c}\text { Journal on Chain } \\
\text { and Network } \\
\text { Science }\end{array}$ & $\begin{array}{l}\text { O setor agrícola de pequenos proprietários da África } \\
\text { Subsaariana enfrenta desafios múltiplos que podem ser } \\
\text { superados pela ação coletiva. A ambidestria é uma } \\
\text { capacidade das redes de inovação de equilibrar a } \\
\text { dinâmica de exploração que é aplicável em vários } \\
\text { níveis: indivíduos, líderes, campeões, equipes e } \\
\text { clusters. No paradigma da inovação aberta, esses níveis } \\
\text { se entrelaçam em estruturas sociais híbridas de redes de }\end{array}$ & Sem indicação. \\
\hline
\end{tabular}




\begin{tabular}{|c|c|c|c|c|c|c|}
\hline & & & & & \begin{tabular}{|c|} 
inovação. O objetivo deste artigo é descrever os papéis \\
e identificar as partes interessadas que desempenham \\
esses papéis em um processo de inovação.
\end{tabular} & \\
\hline 25 & 6 & $\begin{array}{l}\text { Innovation and tradition- } \\
\text { based firms: a multiple case } \\
\text { study in the agro-food sector }\end{array}$ & $\begin{array}{l}\text { Della Corte et } \\
\text { al. (2018) }\end{array}$ & $\begin{array}{c}\text { British Food } \\
\text { Journal }\end{array}$ & $\begin{array}{l}\text { O objetivo é compreender como empresas familiares de } \\
\text { alimentos com tradições de longa data podem } \\
\text { implementar produções inovadoras, enquanto } \\
\text { permanecem ancoradas no passado. Empresas } \\
\text { familiares de alimentos bem-sucedidas alavancam seu } \\
\text { conhecimento da família e tradições locais para inovar. } \\
\text { Ao mesmo tempo, eles estabelecem fluxos contínuos de } \\
\text { troca de informações com partes interessadas, adotando } \\
\text { inovação aberta. } \\
\end{array}$ & $\begin{array}{l}\text { Aprofundar estudos de como se } \\
\text { formaliza uma combinação } \\
\text { efetiva de tradição e inovaçãa, } \\
\text { sobretudo nas empresas } \\
\text { familiares. }\end{array}$ \\
\hline 26 & 6 & $\begin{array}{l}\text { Borderless ideas - open } \\
\text { innovation in the Hungarian } \\
\text { food chain }\end{array}$ & $\begin{array}{c}\text { Fertő et al. } \\
\text { (2016) }\end{array}$ & $\begin{array}{c}\text { British Food } \\
\text { Journal }\end{array}$ & \begin{tabular}{|c|} 
Investiga o desempenho da inovação na cadeia \\
alimentar húngara usando o conceito de inovação \\
aberta. Analisa o desempenho da inovação levando em \\
consideração não apenas os impactos diretos de fluxos \\
externos de conhecimento e capacidade de absorção, \\
mas também o efeito indireto do conhecimento externo \\
em fluxos mediados pela existência de recursos \\
internos. \\
\end{tabular} & $\begin{array}{l}\text { Recomenda-se estender o } \\
\text { escopo do artigo para } \\
\text { outros países, setores e níveis } \\
\text { da cadeia. }\end{array}$ \\
\hline 27 & 6 & $\begin{array}{l}\text { The role of prior experience, } \\
\text { intellectual property } \\
\quad \text { protection and } \\
\text { communication on trust and } \\
\text { performance in innovation } \\
\text { alliances }\end{array}$ & $\begin{array}{l}\text { Ruitenburg et } \\
\text { al. (2014) }\end{array}$ & \begin{tabular}{|} 
Journal on Chain \\
and Network \\
Science
\end{tabular} & $\begin{array}{l}\text { Investiga o papel dos arranjos formais e não formais de } \\
\text { proteção de propriedade intelectual e da comunicação } \\
\text { na construção e manutenção da confiança e, em última } \\
\text { instância, do desempenho. É importante entender como } \\
\text { experiências anteriores, proteção de propriedade } \\
\text { intelectual e comunicação influenciam o nível de } \\
\text { confiança em uma aliança, e que o nível de confiança } \\
\text { está positivamente relacionado à inovação. }\end{array}$ & Sem indicação. \\
\hline 28 & 5 & $\begin{array}{l}\text { Technology transfer as a } \\
\text { mechanism for dynamic } \\
\text { transformation in the food } \\
\text { sector }\end{array}$ & $\begin{array}{l}\text { Kastelli et al. } \\
\quad(2018)\end{array}$ & $\begin{array}{l}\text { Journal of } \\
\text { Technology } \\
\text { Transfer }\end{array}$ & $\begin{array}{l}\text { Estuda o impacto da transferência de tecnologia no } \\
\text { desempenho empresarial e na competitividade de } \\
\text { jovens empresas europeias de alimentos e bebidas. } \\
\text { Explora se as empresas que usam mecanismos de } \\
\text { transferência de tecnologia apresentam melhores } \\
\text { desempenhos competitivos do que empresas com } \\
\text { estratégias menos abertas. }\end{array}$ & $\begin{array}{l}\text { Casos sobre como transferência } \\
\text { de tecnologia expande bases de } \\
\text { conhecimento e capacidades } \\
\text { das empresas, e o tipo de } \\
\text { iniciativas políticas que } \\
\text { fomentariam esse processo. }\end{array}$ \\
\hline
\end{tabular}

Fonte: Elaborado pelos autores. 
Maximizar os ganhos da troca de conhecimentos com parceiros, universidades, fornecedores e clientes é uma questão relevante e proposta como pesquisa futura pelos autores dos artigos analisados. Além da figura do parceiro, é indicado como uma oportunidade de estudo, o estabelecimento de modelos que padronizem rotinas e aumentem a chance de sucesso no uso da estratégia de inovação aberta na agricultura. Cabe ressaltar que os benefícios advindos dessa estratégia e o uso do conhecimento são apontados por Laitinen et al. (2015), os quais salientam que a inovação aberta permite alcançar novos mercados, se destacar dos concorrentes e aumentar as reservas financeiras. Destaca-se realmente, a necessidade de se desenvolver a inovação em formato de parcerias, pelos países em nível mundial nesses últimos anos e, em especial, no Brasil, dado o panorama de crise econômica e enfrentamento da Covid-19, que trouxe impactos em todos os setores.

Após a leitura qualitativa, os artigos foram classificados. Esse sistema de classificação pretende mapear em que contexto a pesquisa foi realizada, com que enfoque, com qual método de pesquisa, em qual segmento de mercado, sob a influência de qual agente e se houve a exposição de sua nacionalidade ou tipo de inovação gerada. Os resultados da classificação foram condensados na Quadro 4. 
Quadro 4: Resultado da classificação dos artigos.

\begin{tabular}{|c|c|c|c|c|c|c|c|}
\hline RANK & CONTEXTO & FOCO & METÓDO & SEGMENTO & AGENTE & NACIONALIDADE & INOVAÇÃO \\
\hline 1 & $1 \mathrm{~A}$ & $2 \mathrm{~A}$ & $3 \mathrm{E}$ & $4 \mathrm{~A}$ & $5 B$ & $6 \mathrm{~A}, 6 \mathrm{~B}$ & $7 \mathrm{~A}$ \\
\hline 2 & $1 \mathrm{~A}$ & $2 \mathrm{~A}$ & $3 \mathrm{D}$ & $4 \mathrm{~A}$ & $5 \mathrm{~A}, 5 \mathrm{D}$ & $6 \mathrm{~B}$ & $7 \mathrm{E}$ \\
\hline 3 & $1 \mathrm{~A}$ & $2 \mathrm{~B}$ & $3 \mathrm{~F}$ & $4 \mathrm{~A}, 4 \mathrm{C}, 4 \mathrm{D}$ & $5 \mathrm{~B}, 5 \mathrm{D}$ & $6 \mathrm{~B}$ & $7 \mathrm{E}$ \\
\hline 4 & $1 \mathrm{~A}$ & $2 \mathrm{~A}$ & $3 \mathrm{E}$ & $4 \mathrm{~A}$ & $5 B$ & $6 \mathrm{~B}$ & $7 \mathrm{E}$ \\
\hline 5 & $1 \mathrm{~A}$ & $2 \mathrm{~A}$ & $3 \mathrm{E}$ & $4 \mathrm{~A}$ & $5 \mathrm{~A}$ & $6 \mathrm{~B}$ & 7A, 7B, 7C \\
\hline 6 & $1 \mathrm{C}$ & $2 \mathrm{~A}$ & $3 \mathrm{~F}$ & $4 \mathrm{~A}$ & $5 B$ & $6 \mathrm{~F}$ & $7 \mathrm{~A}$ \\
\hline 7 & $1 \mathrm{~A}$ & $2 \mathrm{~A}$ & $3 \mathrm{E}$ & $4 \mathrm{~A}$ & $5 \mathrm{~A}$ & $6 \mathrm{~B}$ & $7 \mathrm{E}$ \\
\hline 8 & $1 \mathrm{~B}$ & $2 \mathrm{~A}$ & $3 \mathrm{~F}$ & $4 \mathrm{~A}, 4 \mathrm{C}, 4 \mathrm{D}$ & $5 B$ & $6 \mathrm{C}$ & $7 \mathrm{E}$ \\
\hline 9 & $1 \mathrm{C}$ & $2 \mathrm{~B}$ & $3 \mathrm{~F}$ & $4 \mathrm{~A}$ & $5 \mathrm{~B}$ & $6 \mathrm{~F}$ & $7 \mathrm{~A}$ \\
\hline 10 & $1 \mathrm{~A}$ & $2 \mathrm{~A}$ & $3 \mathrm{E}$ & $4 \mathrm{~A}$ & $5 B$ & $6 \mathrm{~B}$ & $7 \mathrm{~A}$ \\
\hline 11 & $1 \mathrm{~A}$ & $2 \mathrm{~A}$ & $3 \mathrm{E}$ & $4 \mathrm{~A}$ & $5 B$ & $6 \mathrm{~B}$ & $7 \mathrm{E}$ \\
\hline 12 & $1 \mathrm{~A}$ & $2 \mathrm{~A}$ & $3 \mathrm{~B}$ & $4 \mathrm{E}$ & $5 \mathrm{D}$ & $6 \mathrm{~B}$ & $7 \mathrm{E}$ \\
\hline 13 & $1 \mathrm{~B}$ & $2 \mathrm{~A}$ & $3 \mathrm{D}$ & $4 \mathrm{~A}$ & $5 B$ & $6 \mathrm{C}$ & $7 \mathrm{E}$ \\
\hline 14 & $1 \mathrm{~A}$ & $2 \mathrm{~A}$ & $3 \mathrm{E}$ & $4 \mathrm{~A}$ & $5 \mathrm{~B}$ & $6 \mathrm{~B}$ & $7 \mathrm{~A}$ \\
\hline 15 & $1 \mathrm{~A}$ & $2 \mathrm{~A}$ & $3 \mathrm{~F}$ & $4 \mathrm{~A}$ & $5 \mathrm{~A}$ & $6 \mathrm{~B}$ & $7 \mathrm{E}$ \\
\hline 16 & $1 \mathrm{~A}$ & $2 \mathrm{~A}$ & $3 \mathrm{E}$ & $4 \mathrm{~A}$ & $5 \mathrm{D}$ & $6 \mathrm{~B}$ & 7A, 7B \\
\hline 17 & $1 \mathrm{C}$ & $2 \mathrm{~A}$ & $3 \mathrm{~A}$ & $4 \mathrm{~B}$ & $5 \mathrm{E}$ & $6 \mathrm{~F}$ & $7 \mathrm{E}$ \\
\hline 18 & $1 \mathrm{~A}$ & $2 \mathrm{~A}$ & $3 \mathrm{E}$ & $4 \mathrm{~A}$ & $5 B$ & $6 \mathrm{~B}$ & $7 \mathrm{E}$ \\
\hline 19 & $1 \mathrm{~A}$ & $2 \mathrm{~A}$ & $3 \mathrm{E}$ & $4 \mathrm{E}$ & $5 \mathrm{D}$ & $6 \mathrm{~B}$ & $7 \mathrm{E}$ \\
\hline 20 & $1 \mathrm{~A}$ & $2 \mathrm{~B}$ & $3 \mathrm{~F}$ & $4 \mathrm{~A}$ & $5 \mathrm{~A}$ & $6 \mathrm{~B}$ & $7 \mathrm{E}$ \\
\hline 21 & $1 \mathrm{~A}$ & $2 \mathrm{~A}$ & $3 \mathrm{~A}, 3 \mathrm{~B}$ & $4 \mathrm{E}$ & $5 B$ & $6 \mathrm{~B}$ & $7 \mathrm{E}$ \\
\hline 22 & 1B & $2 \mathrm{~A}$ & $3 \mathrm{E}$ & $4 \mathrm{D}$ & $5 \mathrm{D}$ & $6 \mathrm{C}$ & $7 \mathrm{E}$ \\
\hline 23 & $1 \mathrm{~B}$ & $2 \mathrm{~A}$ & $3 \mathrm{E}$ & $4 \mathrm{~A}$ & $5 \mathrm{D}$ & $6 \mathrm{~A}, 6 \mathrm{~B}, 6 \mathrm{C}, 6 \mathrm{D}$ & $7 \mathrm{E}$ \\
\hline 24 & $1 \mathrm{~B}$ & $2 \mathrm{~A}$ & $3 \mathrm{E}$ & $4 \mathrm{~A}$ & $5 \mathrm{~A}$ & $6 \mathrm{D}$ & $7 \mathrm{E}$ \\
\hline 25 & $1 \mathrm{~A}$ & $2 \mathrm{~A}$ & $3 \mathrm{E}$ & $4 \mathrm{~A}$ & $5 B$ & $6 \mathrm{~B}$ & $7 \mathrm{E}$ \\
\hline 26 & $1 \mathrm{~A}$ & $2 \mathrm{~A}$ & $3 \mathrm{D}$ & $4 \mathrm{~A}$ & $5 \mathrm{~A}, 5 \mathrm{~B}, 5 \mathrm{C}$ & $6 \mathrm{~B}$ & $7 \mathrm{E}$ \\
\hline 27 & $1 \mathrm{~A}$ & $2 \mathrm{~B}$ & $3 \mathrm{~F}$ & $4 \mathrm{~A}$ & $5 \mathrm{~A}, 5 \mathrm{~B}, 5 \mathrm{C}$ & $6 \mathrm{~B}$ & $7 \mathrm{E}$ \\
\hline 28 & $1 \mathrm{~A}$ & $2 \mathrm{~A}$ & $3 \mathrm{~F}$ & $4 \mathrm{~A}$ & $5 \mathrm{~B}$ & $6 \mathrm{~B}$ & $7 \mathrm{E}$ \\
\hline
\end{tabular}

Fonte: Elaborado pelos autores.

Legenda: 1A - Países desenvolvidos, 1B - Países em desenvolvimento, 1C - Não se aplica; 2A - Open Innovation como principal tema, 2B - Open Innovation como suporte à teoria; 3A - Qualitativa, 3B - Quantitativa, 3C - Teórica, 3D - Empírica, 3E - Estudos de casos, 3F - Survey; 4A - Agricultura e pecuária, 4B - Caça e pesca, 4C - Mineração, 4D - Extrativismo vegetal, 4E - Não se aplica; 5A - Produtores, 5B - Agroindústrias, 5C - Distribuidores, 5D - Governos, 5E - Não se aplica ; 6A - América, 6B - Europa, 6C Ásia, 6D - África, 6E - Oceania, 6F - Não se aplica; 7A - Produto, 7B - Processo, 7C Organizacional, 7D - Marketing, 7E - Não se aplica.

Para facilitar a visualização dos dados, construiu-se um gráfico para cada classificação realizada, como mostrado abaixo. Em um mesmo periódico, pode haver uma indicação de duas letras na mesma variável. 
Gráfico 1: Variável contexto

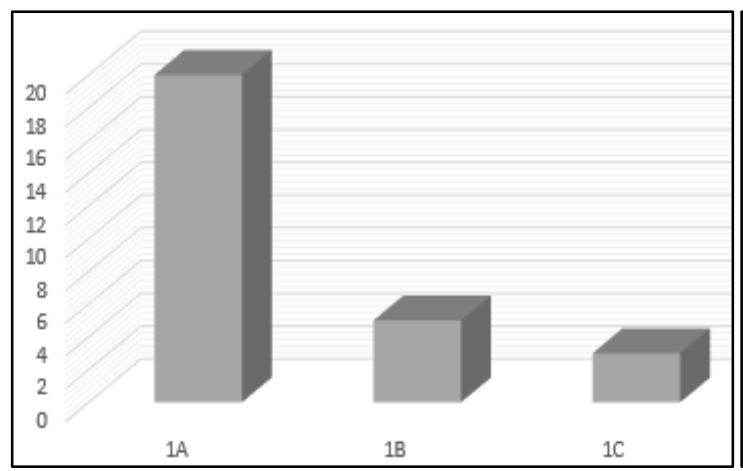

Fonte: Elaborado pelos autores.

As pesquisas sobre inovação aberta na agricultura estão concentradas nos países desenvolvidos (Gráfico 1), o que pode ser explicado pelo volume de capital investido em ciência e tecnologia por esses países, pela concentração dos principais atores, e pelo financiamento de apoiadores da estratégia de inovação aberta. Apenas cinco artigos orientaram seus estudos em países em desenvolvimento, oportunidades para novos estudos acadêmicos. A Europa é a região do globo que mais publicou sobre o assunto (Gráfico 2), podendo-se inferir pelo forte vínculo dos países do continente europeu às questões sustentáveis em diferentes frentes. A Oceania é a única região que não pontuou na variável nacionalidade entre os artigos analisados.

A literatura trata da inovação aberta como $\mathrm{o}$ assunto principal (Gráfico 3), retratando a grande maioria

Gráfico 3: Variável foco

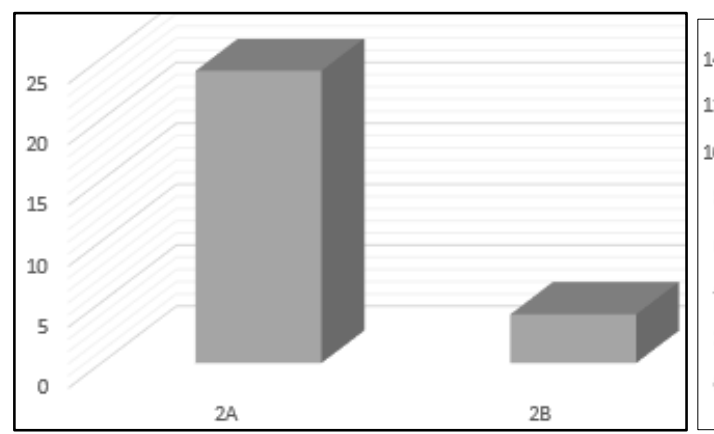

Fonte: Elaborado pelos autores.
Gráfico 2: Variável nacionalidade

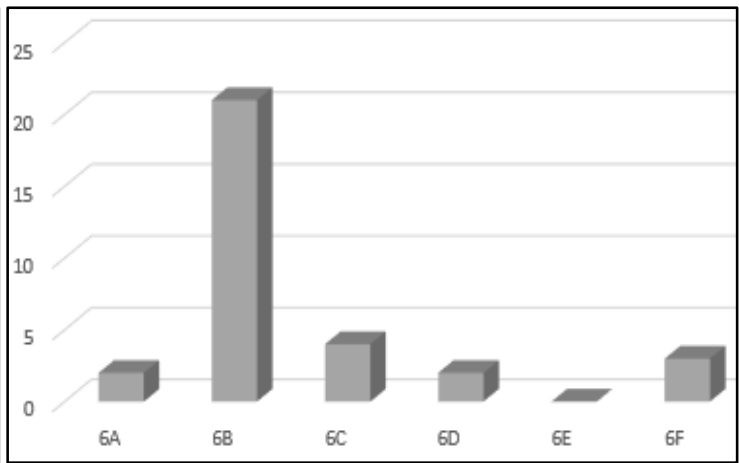

das experiências e pesquisas em estudos de caso e surveys (Gráfico 4). Embora esses métodos sejam comumente usados para descobrir realidades de negócios, verificou-se que metodologias quantitativas deveriam ser melhor utilizadas pela academia.

Somente nos artigos "Finding the right partners: institutional and personal modes of governance of university-industry interactions", "The interaction between inter-firm and interlocking directorate networks on firm's new product development outcomes" e "The role of prior experience, intellectual property protection and communication on trust and performance in innovation alliances" a inovação aberta é discutida a partir de uma perspectiva secundária, ou seja, trabalha-se o efeito da inovação aberta e não, especificamente, como um tópico principal.

Gráfico 4: Variável método de pesquisa

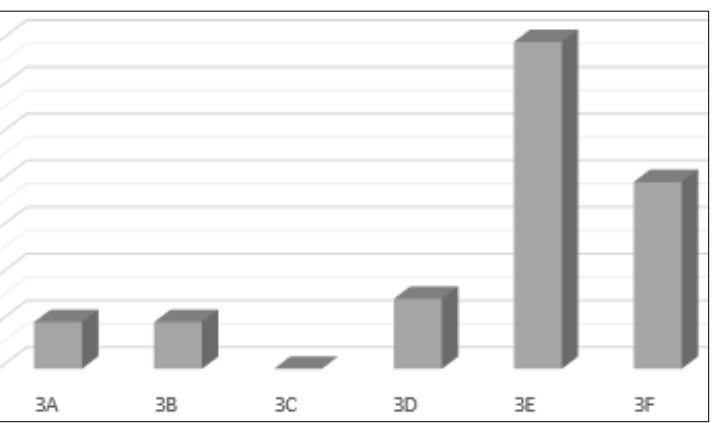


Observa-se que a literatura sobre inovação aberta está concentrada no segmento agropecuário (Gráfico 5), cujos agentes produtor e agroindústria receberam o maior número de estudos (Gráfico 6). Esses agentes se concentram na capacidade de criar inovação na cadeia, e têm poder e influência comercial. $\mathrm{O}$ agente governamental também aparece com

Gráfico 5: Variável segmento

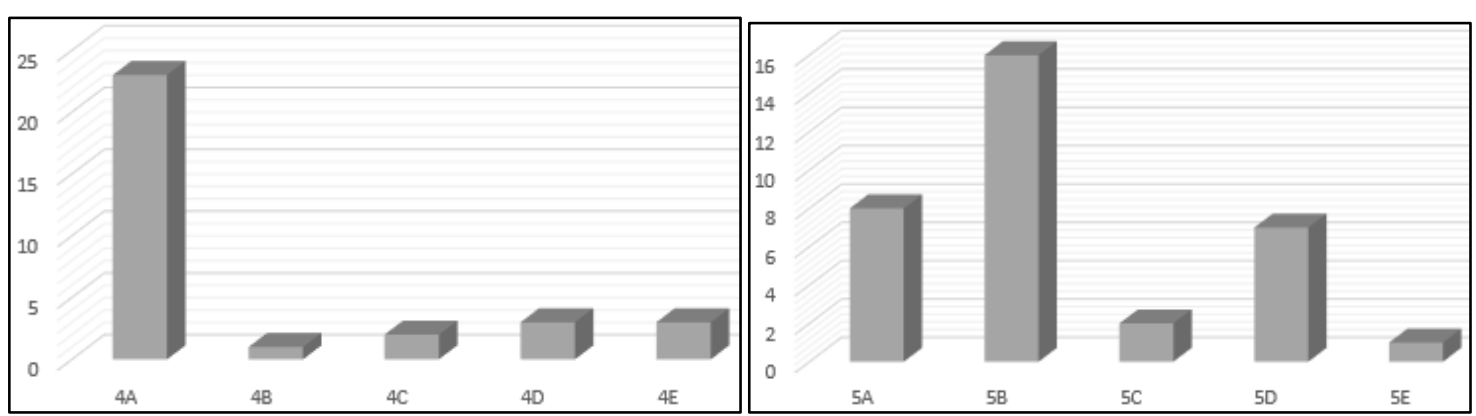

Fonte: Elaborado pelos autores.

O gráfico 7 mostra que em apenas 10 artigos analisados há relatos de que a inovação aberta simplificou o processo de geração de inovação de produto, processo e organizacional. Como regra, a estratégia de inovação aberta é abordada como um todo, sem uma quantidade significativa de estudos, vendo inovação aberta com natureza estratégica e diferenciadora entre os países controladores de mercado. Os segmentos de caça e pesca, mineração e extração de plantas têm poucos artigos na amostra da literatura, o que constitui uma lacuna que pode ser explorada como objeto de pesquisas futuras.
Gráfico 6: Variável do agente especificar o tipo de inovação que a mesma promoveu. Assim, é difícil saber, por meio da literatura, que tipo de inovação poderia ser iniciada primeiro, como um caminho facilitador para governos e empresários.

Gráfico 7: Variável tipo de inovação

Fonte: Elaborado pelos autores.

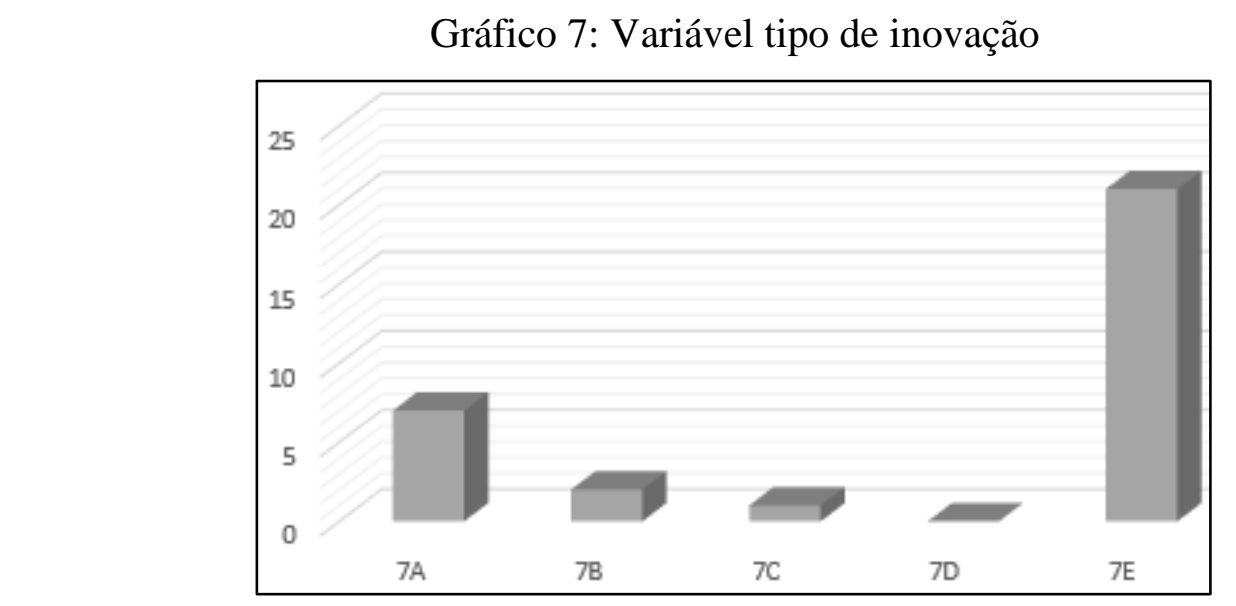

Além disso, não houve discussão sobre inovação de marketing na amostra de artigos. Devido ao seu potencial de ganhos de mercado, um estudo de inovação aberta, voltado para ações de

marketing, em particular junto a pequenos produtores e agroindústrias, e em países em desenvolvimento, é uma lacuna de pesquisa. 


\section{CONSIDERAÇÕES FINAIS}

Considera-se que o objetivo proposto neste artigo foi alcançado, uma vez que (de modo criterioso) foram apresentados os resultados de uma revisão sistematizada sobre inovação aberta na agricultura. Como resultado do estudo de palavras-chaves, entendese que ações envolvendo inovação de processos, empreendedorismo, mudanças climáticas e sustentabilidade, gestão do conhecimento e desenvolvimento de novos produtos podem facilitar o processo de inovação aberta na agricultura.

$\mathrm{Na}$ classificação dos artigos, os dados indicam que a pesquisa sobre inovação na agricultura é realizada, na maioria dos artigos analisados, por países desenvolvidos, no continente europeu e, em geral, a inovação aberta é abordada como um todo, sem especificar o tipo de inovação gerada. Além disso, os agentes mais envolvidos na implementação da inovação aberta seriam produtor e agroindústria, os concentradores do poder, do aprendizado e conhecimento. A agropecuária é o segmento com maior representação no volume de publicações. Os dados também devem ser analisados como indicadores de estímulo ao fomento da pesquisa sobre inovação aberta no Brasil. Por ser um dos grandes players agrícolas, os investimentos direcionados para tais estudos permitiriam contribuir na consolidação desses negócios no país.

Como contribuição, foram levantados pontos, ao longo do estudo dos artigos, que podem ser considerados oportunidades de pesquisa, principalmente as descritas no Quadro

\section{REFERÊNCIAS BIBLIOGRÁFICAS}

AMUI, L. B. L. et al. Sustainability as a dynamic organizational capability: a systematic review and a future agenda
2. Além disso, os agentes rurais podem usar este estudo para melhorar o desempenho da inovação aberta em seus estabelecimentos, concentrando-se esforços para estabelecer relacionamentos com parceiros $\mathrm{e}$ diversos segmentos.

\section{Limitação e pesquisas futuras}

Por ser de natureza teórica e de revisão, o artigo possui caráter exploratório na análise e, devido ao método empregado, é impossível fazer generalizações estatísticas. Outro ponto limitador é o de artigos submetidos à avaliação de alguns países, com predominância de países desenvolvidos, sendo viável para uma dada cultura e comportamento. Os filtros de exclusão adotados podem ter desconsiderado materiais importantes para a análise da literatura.

Como oportunidades para pesquisas futuras, sugere-se expandir os strings de busca, inserindo palavras como barreiras à inovação aberta, gerenciamento de conhecimento e tecnologias digitais. Estudos empíricos, com formulação de hipóteses, sobre como os agentes dos sistemas agroalimentares se comportam na implementação da estratégia de inovação aberta - tentando identificar as limitações para a massificação dessa estratégia no ambiente rural - são bemvindos à literatura. Da mesma forma, estudos comparativos de inovação aberta entre participantes dos mercados de países desenvolvidos e em desenvolvimento também são passíveis de investigação. toward a sustainable transition. Journal of Cleaner Production, v. 142, p. 308322, 2017. 
ANGUE, K. et al. A method using two dimensions of the patent classification for measuring the technological proximity: an application in identifying a potential $R \& D$ partner in biotechnology. The Journal of Technology Transfer, v. 39, n. 5, p. 716-747, 2014.

AZMI, I. M. \& ALAVI, R. Patents and the practice of open science among government research institutes in Malaysia: The case of Malaysian Rubber Board. World Patent Information, v. 35, p. 235-242, 2013.

BARTOLUCCI, C. et al. Green nanomaterials fostering agrifood sustainability. TrAC Trends in Analytical Chemistry, v. 125, p. 115840, 2020.

BERTHET, E. T. et al. Opening design and innovation processes in agriculture: insights from design and management sciences and future directions. Agricultural Systems, v. 165, p. 111$115,2018$.

BIANCHI, M. et al. Organisational modes for open innovation in the biopharmaceutical industry: an exploratory analysis. Technovation, v. 31, p. 22-33, 2011.

BIOLCHINI, J. C. A. et al. Scientific research ontology to support systematic review in software engineering. Advanced Engineering Informatics, v. 21, n. 2, p. 133-151, 2007.

BODAS FREITAS, I. M. et al. Finding the right partners: institutional and personal modes of governance of university-industry interactions. Research Policy, v. 42, p. 50-62, 2013.
BORGES, M. et al. Open Innovation: Research, Practices, and Policies. California Management Review, v. 60, n. 2, p.5-16, 2018.

CHEGE, S. M. \& WANG, D. The influence of the entrepreneur's open innovation strategy on firm performance. Information Resources Management Journal, v. 32, n. 4, p. 20-41, 2019.

CHESBROUGH, $H$. et al. Value creation and value capture in Open Innovation. Journal of Product Innovation Management, v. 35, n. 6, p.930-938, 2018.

CHESBROUGH, H. W. Open innovation. Research Technology Management, special issue, p. 20-27, 2012.

CHESBROUGH, H. W. Open innovation: a new paradigm for understanding industrial innovation. In: CHESBROUGH, $\mathrm{H}$. W.; VANHAVERBEKE, W. J. Open innovation: researching a new paradigm. New York: Oxford University Press, 2006.

CHESBROUGH, H. W.; GARMAN, A. R. How open innovation can help you cope in lean times. Harvard Business Review, v. 87, n. 12, p. 68-76, 2009.

CILLO, V. et al. Knowledge management and open innovation in agri-food crowdfunding. British Food Journal, v. 121, n. 2, p. 242-258, 2019.

DAHABIEH, M. S. et al. Overcoming barriers to innovation in food and agricultural biotechnology. Trends in Food Science \& Technology, v. 79, p. 204-213, 2018.

DELLA CORTE, V. et al. Innovation and tradition-based firms: a multiple 
case study in the agro-food sector.

British Food Journal, v. 120, n. 6, p. 1295-1314, 2018.

DRAGONE, G. et al. Innovation and strategic orientations for the development of advanced biorefineries. Bioresource Technology, v. 302, p. 122847, 2020.

DRIES, L. et al. Keeping Your Secrets Public?: Open Versus Closed Innovation Processes in the Hungarian Wine Sector. International Food and Agribusiness Management Review, v. 17, n. 1, p.147-162, 2014.

DRIES, L. et al. Open innovation: a case-study of the Hungarian wine sector. EuroChoices, v. 12, n. 1, p. 5359, 2013.

FAURE, G. et al. How different agricultural research models contribute to impacts: evidence from 13 case studies in developing countries. Agricultural Systems, v. 165, p. 128136, 2018.

FERTÖ, I. et al. Borderless ideas - open innovation in the Hungarian food chain. British Food Journal, v. 118, n. 6, p. 1494-1515, 2016.

FIORINI, P. C. et al. Management theory and big data literature: from a review to a research agenda. International Journal of Information Management, v. 43, p. 112-129, 2018.

\section{FOOD AND AGRICULTURE} ORGANIZATION OF THE UNITED STATES (FAO). Estudo revela que Brasil é um dos países mais eficientes no uso da terra e insumos agrícolas em função de sua alta produção. $2017 . \quad$ Disponível em: <http://www.fao.org/brasil/noticias/deta il-events/en/c/1070557/>. Acesso em: 27 fev. 2020.

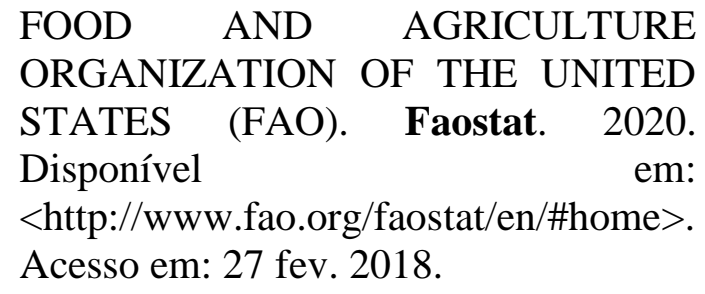

GOVINDAN, K. et al. Reverse logistics and closed-loop supply chain: a comprehensive review to explore the future. European Journal Of Operational Research, v. 240, n. 3, p. 603-626, 2015.

JABBOUR, C. J. C. Environmental training in organisations: from a literature review to a framework for future research. Resources, Conservation and Recycling, v. 74, p. 144-155, 2013.

JOFFRE, O. M. et al. How is innovation in aquaculture conceptualized and managed? A systematic literature review and reflection framework to inform analysis and action. Aquaculture, v. 470, p. 129-148, 2017.

KASTELLI, I. et al. Technology transfer as a mechanism for dynamic transformation in the food sector. The Journal of Technology Transfer, v. 43, p. 882-900, 2018.

KHAN, S. A. \& BOHNSACK, R. Influencing the disruptive potential of sustainable technologies through value proposition design: the case of vehicleto-grid technology. Journal of Cleaner Production, v. 254, p. 120018, 2020.

KLERKX, L. \& NETTLE, R. Achievements and challenges of innovation co-production support initiatives in the Australian and Dutch dairy sectors: a comparative study. Food Policy, v. 40, p. 74-89, 2013. 
KRATZER, J. et al. Open innovation and company culture: internal openness makes the difference. Technological Forecasting \& Social Change, v. 119, p. 128-138, 2017.

KWON, S. How does patent transfer affect innovation of firms? Technological Forecasting \& Social Change, v. 154, p. 119959, 2020.

LAITINE et al. Product knowledge and lifecycle management in project-based manufacturing. Applied Mechanics and Materials. p. 1283-1287, 2015.

LAWAL, I. A. et al. Brief bibliometric analysis of "ionic liquid" applications and its review as a substitute for common adsorbent modifier for the adsorption of organic pollutants. Environmental Research, v. 175, p. 34-51, 2019.

LECKEL, A. et al. Local open innovation: a means for public policy to increase collaboration for innovation in SMEs. Technological Forecasting and Social Change, v. 153, p. 119991, 2020.

LIU, H-Y. et al. Genetic and agronomic traits stability of marker-free transgenic wheat plants generated from Agrobacterium-mediated co transformation in $\mathrm{T} 2$ and $\mathrm{T} 3$ generations. Journal of Integrative Agriculture, v. 19, n. 1, p. 23-32, 2020.

LONG et al. Barriers to the adoption and diffusion of technological innovations for climate-smart agriculture in Europe: evidence from the Netherlands, France, Switzerland and Italy. Journal of Cleaner Production, v. 112, p. 9-21, 2016.

LONG, T. B.; BLOK, V. Integrating the management of socio-ethical factors into industry innovation: towards a concept of Open Innovation 2.0. International Food and Agribusiness Management Review, v. 21, n. 4, p.463-486, 2018.

MALIK, K. et al. Developing new technology platforms for new business models: Syngenta's partnership with the university of Manchester. Research Technology Management, p.24-31, 2011.

MAZZOLA, E. et al. Network embeddedness and new product development in the biopharmaceutical industry: the moderating role of open innovation flow. International Journal of Production Economics, v. 160, p. 106-119, 2015.

MAZZOLA, E. et al. The interaction between inter-firm and interlocking directorate networks on firm's new product development outcomes. Journal of Business Research, v. 69, p. 672-682, 2016.

MCADAM, M. et al. Development of small and medium-sized enterprise horizontal innovation networks: UK agri-food sector study. International Small Business Journal, v. 32, n. 7, p. 830-853, 2014.

MEDEIROS, G. I. B. et al. Evidences of open innovation in Brazilian agrifood chain. Espacios, v. 38, n. 28, p. 2, 2017.

MEHLMAN, S. K. et al. Better practices for managing intellectual assets in collaborations. ResearchTechnology Management, v. 53, n. 1, p. 55-66, 2010.

MEYNARD, J-M. et al. Designing coupled innovations for the sustainability transition of agrifood systems. Agricultural Systems, v. 157, p. 330-339, 2017. 
MICHLER, J. D. Agriculture in the process of development: a microperspective. World Development, v. 129, p. 104888, 2020.

MORAES, F. P. \& COLLA, L. M. Alimentos funcionais e nutracêuticos: definições, legislação e benefícios à saúde. Revista Eletrônica de Farmácia, v. 3, n. 2, p. 109-122, 2006.

NILE, S. H. et al. Nanotechnologies in food science: applications, recent trends, and future perspectives. NanoMicro Letters, v. 12, n. 45, 1-34, 2020.

OCHARA, N. M \& MORO, C. Editors preface: towards open innovation in the fourth industrial revolution. 2018 Open Innovation Conference, v. 8535813, IVI, 2018.

OSORIO-GARCÍA, A. M. et al. Can an innovation platform support a local process of climate-smart agriculture implementation? A case study in Cauca, Colombia. Agroecology and Sustainable Food Systems, v. 44, n. 3, p. 378-411, 2020.

PÉREZ PERDOMO, S. A. et al. Stakeholder roles for fostering ambidexterity in Sub-Saharan African agricultural netchains for the emergence of multi-stakeholder cooperatives. Journal on Chain and Network Science, v. 16, n. 1, p. 59-82, 2016.

PETRONI, G. et al. Open innovation and new issues in $R \& D$ organization and personnel management. The International Journal of Human Resource Management, v. 23, n. 1, p. 147-173, 2012.

PIVOTO et al. Scientific development of smart farming technologies and their application in Brazil. Information Processing in Agriculture, v. 5, p. 2132, 2018.
REDEKER, G. A. et al. Lean information for lean communication: analysis of concepts, tools, references, and terms. International Journal of Information Management, v. 47, p. 31-43, 2019.

ROBERTSON, P. L. et al. Managing open incremental process innovation: absorptive capacity and distributed learning. Research Policy, v. 41, n. 5, p. 822-832, 2012.

ROUCAN-KANEA, M. et al. U.S. Agribusiness Companies and Product Innovation: Insights from a Choice Experiment Conducted with Agribusiness Executives. International Food and Agribusiness Management Review, v. 4, n. 16, p.123-140, 2013.

RUITENBURG, R. J. et al. The role of prior experience, intellectual property protection and communication on trust and performance in innovation alliances. Journal on Chain and Network Science, v. 14, n. 2, p. 117128, 2014.

SCHOTTEN, M. et al. A brief history of Scopus: the world's largest abstract and citation database of scientific literature. In: CANTU-ORTIZ, F. J. Research Analytics: boosting university productivity and competitiveness through scientometrics. 1. ed. Boca Raton, FL: Taylor \& Francis Group, 2017. p. 31-58.

SPECHT, K. et al. Application and evaluation of a participatory "open innovation" approach (ROIR): The case of introducing zero-acreage farming in Berlin. Landscape and Urban Planning, v. 151, p.45-54, 2016.

TEECE, D. J. et al. Dynamic capabilities and strategic management. 
Strategic Management Journal, v. 18, n. 7, p. 509-533, 1997.

VAC, C. S. \& FITIU, A. Building sustainable development through technology transfer in a Romanian University. Sustainability, v. 9, n. 11, 2042, 2017.

VILLA-HENRIKSEN, A. et al. Internet of things in arable farming: implementation, applications, challenges, and potential. Biosystems Engineering, v. 191, p. 60-84, 2020.

VILLASALERO, M. University knowledge, open innovation and technological capital in Spanish science parks: research revealing or technology selling? Journal of Intellectual Capital, v. 15, n. 4, p. 479-496, 2014.
WOLFERT, J. et al. Organizing information integration in agri-food - a method based on a service-oriented architecture and living lab approach. Computers and Electronics in Agriculture, v. 70, n. 2, p.389-405, 2010.

ZHAO, Y. et al. An effective automatic system deployed in agricultural internet of things using multi-context fusion network towards crop disease recognition in the wild. Applied Soft Computing, v. 89, p. 106128, 2020.

ZHU, J.; LIU, W. A tale of two databases: the use of Web of Science and Scopus in academic papers. Scientometrics, v. 123, n. 1, p. 321335, 2020. 